\title{
Neurocognitive control in dance perception and performance
}

Article

Accepted Version

Blaesing, B., Calvo-Merino, B., Cross, E. S., Jola, C., Honisch, J. and Stevens, C. (2012) Neurocognitive control in dance perception and performance. Acta Psychologica, 139 (2). pp. 300-308. ISSN 0001-6918 doi:

https://doi.org/10.1016/j.actpsy.2011.12.005 Available at https://centaur.reading.ac.uk/42652/

It is advisable to refer to the publisher's version if you intend to cite from the work. See Guidance on citing.

To link to this article DOI: http://dx.doi.org/10.1016/j.actpsy.2011.12.005

Publisher: Elsevier

All outputs in CentAUR are protected by Intellectual Property Rights law, including copyright law. Copyright and IPR is retained by the creators or other copyright holders. Terms and conditions for use of this material are defined in the End User Agreement.

\section{www.reading.ac.uk/centaur}

\section{CentAUR}

Central Archive at the University of Reading 
Reading's research outputs online 
Neurocognitive Control in Dance Perception and Performance

Bettina Bläsing ${ }^{1}$, Beatriz Calvo-Merino ${ }^{2}$, Emily S. Cross ${ }^{3}$, Corinne Jola ${ }^{4}$, Juliane Honisch $^{5}$ and Catherine J. Stevens ${ }^{6}$

${ }^{1}$ Department of Sport Science and Center of Excellence Cognitive Interaction Technology (CITEC), Bielefeld University, Germany

${ }^{2}$ Department of Psychology, Universidad Complutense Madrid, Spain and Department of Psychology, City University, London, United Kingdom

${ }^{3}$ Department of Social \& Cultural Psychology, Radboud University Nijmegen, The Netherlands and School of Psychology, Bangor University, Gwynedd, United Kingdom

${ }^{4}$ Department of Psychology, University of Surrey, United Kingdom

${ }^{5}$ Department of Psychology, University of Birmingham, United Kingdom

${ }^{6}$ MARCS Auditory Laboratories and School of Psychology, University of Western Sydney, Australia

Running Head: Neurocognitive control in dance

Address for correspondence:

Dr. Bettina Bläsing

Neurocognition and Action Research Group

Department of Sport Science

Bielefeld University

PB 100131

33501 Bielefeld

Germany

Email: bettina.blaesing@uni-bielefeld.de 


\begin{abstract}
Dance is a rich source of material for researchers interested in the integration of movement and cognition. The multiple aspects of embodied cognition involved in performing and perceiving dance have inspired scientists to use dance as a means for studying motor control, expertise, and action-perception links. The aim of this review is to present basic research on cognitive and neural processes implicated in the execution, expression, and observation of dance, and to bring into relief contemporary issues and open research questions. The review addresses six topics: 1) dancers' exemplary motor control, in terms of postural control, equilibrium maintenance, and stabilization; 2) how dancers' timing and on-line synchronization are influenced by attention demands and motor experience; 3) the critical roles played by sequence learning and memory; 4) how dancers make strategic use of visual and motor imagery; 5) the insights into the neural coupling between action and perception yielded through exploration of the brain architecture mediating dance observation; and 6) a neuroaesthetics perspective that sheds new light on the way audiences perceive and evaluate dance expression. Current and emerging issues are presented regarding future directions that will facilitate the ongoing dialogue between science and dance.
\end{abstract}

\title{
Keywords
}

Motor control, memory, action observation network, imagery, motor simulation, synchronization, aesthetics. 


\section{Highlights}

1. Dance is a valuable source for studying the integration of movement and cognition.

2. Dance expertise involves motor control, memory for movement, strategic use of imagery, and synchronization.

3. Neural correlates of dance observation yield insight into action-perception coupling and a perceiver's aesthetic experience of watching dance. 
Neurocognitive Control in Dance Perception and Performance

Dance is a universal form of human expression that has been cultivated into various forms and functions (Hanna, 1979). Its origin is intrinsically linked to social interactions (Brown et al., 2005), and it has been thought to exist in similar forms universally across cultures (Grahn \& McAuley, 2009; Phillips-Silver et al. 2011). With the evolution of human societies, the characteristics of dance and dancers have changed over time (Daprati et al., 2009), but typically, dance is associated with one or multiple bodies moving in a specified rhythmical manner with or without music. Dance expertise can be acquired to different degrees of professionalism, often judged according to the performers' physical virtuosity in terms of limb coordination, flexibility, and strength, as well as other performative and aesthetic elements that are more subjectively determined. These latter components are the ones that make the dancer distinguishable from other motor experts such as athletes or martial artists (Yarrow et al., 2009), and they are crucial for psychology and neuroscience studies that aim to investigate the integration of physical virtuosity with aesthetic, affective, communicative and social elements. Both the physical and the artistic demands of dance require manifold cognitive abilities that can be studied using behavioral and neuroscientific methods (Bläsing, Puttke \& Schack, 2010).

Dancers, for example, must learn complex movement sequences by efficiently reproducing movements they observe, which can include the transfer of visual and verbal information into motor action. Dancers modify movements with respect to direction in space, speed, rhythm, and amplitude, and express them precisely as observed from the choreographer's demonstration or in a modified form, depending on the choreographer's wishes. Further, dancers refine movements according to aesthetic and expressive affordances of the choreographer and/or the dance style. When dancing in an ensemble, dancers must remain 
attentive to their fellow dancers in order to synchronize their movement. Thus, dancers are required to generate, observe, execute, and coordinate complex movement patterns demanding the integration of physical and cognitive skills. Dancers' expertise in several movement-related tasks including movement exploration, rehearsal, and performance, can be investigated using experimental methods.

This review examines a number of basic research findings in those areas of dance that can contribute to our understanding of the complex processes required to coordinate the brain and body in highly-skilled action performance and perception. In particular, we review research on cognitive and neural processes implicated in the generation, execution, expression, and observation of dance movements by the dancer and dance spectator. Further, we bring into relief contemporary issues and open research questions in this domain. Along these lines, we ask in what way the study of dance contributes to advancements in knowledge of human cognition and behavior. We examine the scientific validity of using dance-related stimuli and dancers' expertise in order to investigate the nature of the various processes involved in such highly sophisticated motor and cognitive skills. In the spirit of "artscience" (Edwards, 2008) the review may also prompt questions from dance that provoke new ideas and approaches in cognitive science and that ultimately have mutually beneficial outcomes.

From "toe to head", we begin by considering processes of motor control, specifically how dancers maintain balance (equilibrium) in difficult postures, such as in pointe work for female ballet dancers, or in pirouette turns on one leg. The way dancers synchronize their movements with a dance partner, dance ensemble, or a musical beat, is then reviewed. Next, we consider the strategic use of dance sequences as stimuli to shed light on memory encoding, followed by research into visual and motor imagery for dance and in dancers. The close coupling of perception and action in observing and in performing dance is then discussed with particular 
attention given to the neural substrates involved in these processes. Finally, research from the nascent field of dance neuroaesthetics is introduced, with attention focused on what can be learned from the relationship between the dance creator and the dance spectator.

\section{Motor Control}

The increased demand for verticality of ballet postures (Daprati, Iosa, \& Haggard, 2009) puts strenuous requirements on female ballet dancers' flexibility, strength, and balance. One may thus assume that dancers show enhanced abilities in posture control and equilibrium maintenance as a vital part of their expertise. A number of studies have investigated the cognitive control functions that underlie dancers' exceptional physical skill, with a focus on the learning and maintenance of these control functions, and how they may affect other sensorimotor processes.

\subsection{Control of Equilibrium and Posture}

Dance training enhances sensorimotor control functions underlying static as well as dynamic equilibrium. For example, classically-trained dancers exhibit better postural control (Rein, Fabian, Zwipp, Rammelt, \& Weindel, 2011), can maintain given postures for longer durations (Crotts, Thompson, Nahom, Ryan, \& Newton, 1996), and show more vertical alignment during stepping than non-dancers (Chatfield, Krasnow, Herman, \& Blessing, 2007). Several studies revealed better balance skills in dancers compared to non-dancers (Golomer, Dupui, \& Monod, 1997a,b; Golomer, Cremieux, Dupui, Isableu, \& Ohlmann 1999a), in adult dancers compared to younger and less experienced dancers (Bruyneel, Mesure, Paré, \& Bertrand, 2010), and in female compared to male dancers in equilibrium reactions (Golomer, Dupui, \& Monod, 1997b). Even short episodes of breakdance training have been found to increase balance skills in young amateurs (Ricotti \& Ravaschio, 2011). 
Intriguingly, with increased proficiency in dance, somatosensory functions appear to improve with physical training, leading to a changed balance of the individual senses in multimodal processing. For example, enhanced proprioceptive skills associated with dancers' heightened posture control have been suggested to interfere with other sensory processes such as vision (Golomer et al., 1999a; Jola, Davis, \& Haggard, 2011). Dance training has been claimed to increase the relative influence of somatosensation and to shift sensorimotor dominance from vision to proprioception (e.g., Golomer \& Dupui, 2000). Therefore, skilled dancers should have a more accurate position sense based on proprioceptive information, and should rely more on proprioception than on vision compared to non-dancers. Empirical evidence for this hypothesis has been found for dynamic equilibrium tasks among professional ballet dancers (Golomer \& Dupui, 2000), and for position-matching tasks involving matching the hand location in space (Jola, Davis, \& Haggard, 2011; Ramsay \& Riddoch, 2001). In the latter, dancers performed significantly better than controls when only proprioceptive information was available. Surprisingly, however, dancers seemed to rely more on proprioception even when vision was available, leading to a tendency toward higher error rates in the vision-only condition, in which controls are generally more accurate.

In contrast, studies using static equilibrium tasks showed that dancers' balance strategies relate the regulation of self-motion to visual information rather than to somatosensation. Hence, in balance tasks with closed eyes, dancers perform no better than controls (Hugel, Cadopi, Kohler \& Perrin, 1999; Golomer, Dupui, Sereni, \& Monod 1999b) and worse than judo experts (Perrin, Deviterne, Hugel \& Perrot 2002). Nevertheless, dancers' dynamic patterns of postural sway are modulated by visual input in different ways from those of nondancers. Dancers' sway patterns while standing on a foam surface with their eyes closed were found to be more stationary (showing lower trend) and less regular, stable and complex (lower recurrence, mathematical stability, and entropy) than those of track athletes (Schmit, 
Regis, \& Riley, 2005). While dancers generally showed smaller pitch sway oscillations than untrained controls, pitch and roll sway were increased in dancers standing on one leg with the left hemifield occluded, whereas only pitch sway was increased in untrained controls under the same conditions (Golomer, Mbongo, Toussaint, Cadiou \& Israel, 2010).

These findings suggest that sensory control strategies might be task-specific, and that dance training enhances the relative influence of somatosensation, specifically proprioception, on multimodal integration for dynamic equilibrium tasks and position-matching, but not for static equilibrium tasks. Taken together, these studies demonstrate that basic functions underlying the control of equilibrium, posture, and sway are sensitive to training effects, and that dance training has the potential to stabilize and align dancers' performance via these functions. The roles of individual sensory modalities in multimodal integration, especially relative influences of vision and somatosensation deserve further clarification. Such research could focus on issues such as contributions of individual sensory modalities and their integration in balance and posture control. A subsequent question that emerges asks how multimodal integration is modified by dance training.

\subsection{Control of Complex Movements}

The apparently effortless performance of highly demanding moves is a characteristic of skilled dance experts. Dancers achieve this goal by optimizing motor synergies and consequently reducing energy costs in terms of force and muscle tension. In general, kinematic analysis shows that classical dancers have the ability to efficiently combine movements of related joints into single motor synergies, thus reducing the number of degrees of freedom at the level of neuronal control. This leads to highly accurate reproduction of the orientation and shape of the required trajectories (Thullier \& Moufti, 2004; Wilson, Lim, \& Kwon, 2004). Lepelley, Thullier, Koral, and Lestienne (2006) found that skilled ballet 
dancers selectively applied minimal muscle tension at the reversal point of ballistic leg movements from their classical repertoire, even though torque was maximal in this position.

Whole body rotations, especially unipedal turns such as pirouettes, require stabilization of the turning axis through the supporting leg, as well as alignment of shoulders and hips over the same axis. Skilled dancers, in contrast to controls, were capable of maintaining shoulders and hips en bloc during different kinds of turns, independent of turning direction and laterality of the supporting leg (Golomer, Touissant, Bouillette \& Keller, 2009b). The ability to control unipedal turns also depends on the starting posture, and dancers have been found to optimize the relation of foot distance and weight distribution during the preparation of the turn (Sugano \& Laws, 2002).

Interestingly, individual preference for turning direction might strongly influence dancers' skills in performing whole body turns. A rightward turning bias has been described for adult ballet dancers (Golomer, Rosey, Dizac, Mertz \& Fagard, 2009a; Starosta, 2000), whereas untrained controls predominantly showed a leftward turning bias and a weaker dependency between turning bias and leg preference than dancers (Golomer et al., 2009a). From these results it has been concluded that turning bias is sensitive to training effects and that dancers who are specifically trained for symmetry of movement can partly counterbalance such biases. Empirical findings seem to suggest that classical dance training induces a rightward turning tendency; however, it cannot be excluded that individuals with a natural rightward turning bias are more likely to become dancers.

As shown in this section, research investigating the control of specific dance movements revealed dancers' skills in optimizing motor synergies, which leads to reduced muscle tension and increased accuracy of movement. For rotational movements, dancers seem to develop 
specific strategies to stabilize the turning axis and to overcome individual turning biases. Current research issues include the adaptation of neurocognitive control functions to dancers' modified physical abilities, and to challenges such as increased flexibility, efficient patterns of muscle activation, and coordination of novel movements. We should ask how cognitive strategies utilize these functions to advance performance even further, and how such strategies can be acquired during training.

Taken together, the studies presented here show that dance training has the potential to influence basic functions underlying motor control, including multimodal integration as well as posture and equilibrium control, facilitating the performance of complex movements via dancers' special skills in body alignment and balance tasks. Building up on these conditions, dancers can apply specific strategies such as the optimization of motor synergies when executing complicated movement combinations, jumps or turns. Crucially, dancers often develop and apply these strategies in an explicit way that requires attentional processes and makes them accessible for higher cognitive processes, such as the use of imagery, and adaptable to external acoustic or visual cues. Therefore, even though dancers' movement expertise can be examined and described via biomechanical measures (see Krasnow, Wilmerding, Stecyk, Wyon, \& Koutedakis, 2011), physical skills in dance can hardly be regarded separatedly from the cognitive functions and strategies that enable dancers to make use of them in a way that makes dance an art form.

\section{Timing and Synchronization in Dance Performance}

One crucial aspect in any dance performance is timing, which refers to either the synchronization of one's movements to those of another dance partner or to the beat of accompanying music. For example, two dancers in a dance ensemble may start a movement sequence at the same time, follow a dynamic path which refers to the speed and the trajectory 
of the movement, and finish the sequence at the same time. Even in a dance piece that has been newly choreographed by semi-professional dancers, performance with the accompanying soundscape versus performance in silence can elicit a difference in timing across a four-minute piece of only 5\% (Stevens, Schubert, Wang, Kross, \& Halovic, 2009). This negligible variation appears more related to memory lapse than to a miscalibrated internal clock.

Attention is an important factor involved in maintaining synchrony in dance. Mienvielle-Moncla, Macar and Vallet (2008) investigated attentional demands of complex dance sequences and the effects of choreographic complexity on dancers' timing in solo performances, showing that short walking distances as well as high movement complexity increased timing errors due to interference with dancers' attention. As there are observable effects of attention on individual performance, attentional demands in ensemble scenarios are likely even more complex due to the need for synchrony with other dancers. A first step into exploring the dynamics of dance ensemble performance was made by Maduell and Wing (2007), who provided a detailed feedback model with hierarchical control structures in terms of connected networks to simulate the dynamic interaction between members of a flamenco ensemble. Different degrees of control between ensemble members suggested the use of distinct attentional strategies for integrating information from other members based on the member's status within the ensemble. Musical cues have been shown to indicate the appropriateness of specific moves at specific points, but physical contact between dancers facilitates accuracy timing and is robust to differences in musical structure (Gentry \& Feron, 2004). The potential impact of metrical structure in music-induced movement is also beginning to be explored (e.g., Toiviainen, Luck, \& Thompson, 2010). 
Understanding the interactions and control levels within dance ensembles is important to explain how dancers achieve and maintain synchrony within a pair or group. Honisch, Roach, and Wing (2009) investigated interpersonal interactions and their effects on ensemble synchrony. Temporal accuracy was their focus; specifically events such as target positions or dynamic cues to which dancers may synchronize their movements. Expert ballet dancers not only synchronized better with familiar compared with less familiar movements, but they were also more accurate in synchronizing to the dynamics of the movement (e.g. its peak velocity) compared to the target position (endpoint in space; Honisch, Roach, \& Wing, 2009). The results suggest that dancers' timing skills are modulated by motor experience with particular movements. In addition, dancers' anticipation of target positions may enable faster detection and rapid adjustment to errors that may be performed by other dancers.

Dance ensemble coordination and timing is complex, influenced by factors such as attention demands, performer motor experience, and status within an ensemble. Constructing predictive models of real life performances will help explain how successful coordination between multiple dancers can be achieved and facilitated. Such emerging research will also inform, more broadly, theories of ensemble timing, synchronization, and acquired temporal expectations.

\section{Learning and Memory in Dance Perception and Performance}

The complex movement sequences executed by dancers in solos, duets, and ensemble pieces epitomize the human capacity for sequence learning. Research using dance material as stimuli is significant for memory research because, unlike digits, letters, or spatial locations, the tobe-remembered movement items not only extend in time for some seconds, but the sequences of items also unfold over time. A question that arises is how sequences of complex dance movement are coded in human memory. 
The recall of sequences of dance movement is enhanced for structured compared to unstructured sequences. For example, recall performance of expert dancers who had comparable experience in both ballet and modern dance, were significantly greater for sequences of ballet than modern dance (Jean, Cadopi, \& Ille, 2001). A concurrent verbal interference task lowered recall rates slightly, suggesting some verbal rehearsal of to-beremembered dance items and, in a control (no interference) condition, structured sequences were recalled better than unstructured sequences. Working with 11-year-old expert ballet and novice dancers, Strakes, Deakin, Lindley, and Crisp (1987) showed advantages in recall by experts compared with novices, and for structured compared with unstructured ballet sequences. The last elements in the ballet sequence stimuli were also recalled less often, especially when the previously-accompanying music was absent. Smyth and Pendleton (1994) showed that professional ballet dancers recorded longer memory spans than those of nondancers for both ballet and nonsense movements. Relative to non-dancers, the dancers appeared to have enhanced encoding of movement items in general, i.e., dance and non-dance items. In an experiment by Cross, Hamilton, Kraemer, Kelley, and Grafton (2009), nondancers trained on dance steps with accompanying techno music performed significantly better when a human model also performed the dance steps than when visual directional cues (i.e., scrolling arrows) were presented. Individual components of the action observation network appear to respond differently to the human form and to dance training.

Dance experts use a variety of strategies and techniques to encode sequences of movement. For example, they indicate body movements with the hands - so-called "marking" (Allard \& Starkes, 1991; Kirsh, Muntanyola, Jao, Lew, \& Sugihara, 2009), a labor-saving means of rehearsal using reduced range of motion and energy expenditure, which helps to verify 
movement rhythm, direction, and spacing. In addition to its utility as a rehearsal technique, marking likely also serves as a cue for movement recall.

Articulatory suppression and interference have been used as methods to investigate the contribution of verbal, spatial, and/or motor codes in encoding, rehearsing, and recalling series of dance items from working memory (e.g., Jean et al. 2001; Rossi-Arnaud, Cortese, \& Cestari, 2004). Suppression tasks involve performing a task at the same time as observing the to-be-remembered material, and are used to disrupt encoding of the to-be-remembered (TBR) material. Interference tasks, such as a word or location-tapping task, intervene between presentation of the material and recall, and are used to disrupt rehearsal using a verbal or spatial process, respectively. The logic of these paradigms is that if, for example, the TBR material is encoded and/or rehearsed using a verbal code, then a concurrent verbal task but not a concurrent motor or spatial task, should reduce recall of the TBR material. Smyth and Pendleton (1990) advocated for a kinesthetic-spatial system in working memory. They proposed that in spatial memory the location of a target in space is the goal for an action, whereas in memory for movement the configuration of the body parts is the goal. In a recent experiment, concurrent spatial interference (tapping four visuo-spatial targets) did not affect memory for ballet moves by ballet dancers; this result was interpreted as evidence in support of a system for motor configurations in working memory (Cortese \& Rossi-Arnaud, 2010).

Serial position data tend to reveal primacy but not recency effects in short-term memory for ballet steps (Allard \& Starkes, 1991; Starkes et al. 1987), implying that movement items are chained. An informative contrasting result is the presence of both primacy and recency effects when the to-be-remembered material is modern dance (Starkes, Caicco, Boutilier, \& Sevsek, 1990). Starkes et al. (1990) interpret this finding in light of modern dance differing from ballet with fewer established verbal labels in modern dance and the possibility that "lack of 
structure may become an important cue in and of itself" (p. 320). Thus, conditions under which primacy and recency effects occur warrant further investigation. Recall may be greater when there is some higher-level ordinal and/or temporal structure including more biologically plausible flow between movement items. The use of more ecologically valid dance material as stimuli in memory studies is increasing and will enable comparison across dance genres. Primacy and recency effects are likely to be useful tools to examine chaining or hierarchical structuring in memory for dance.

Knowledge structures in long-term memory for dance are influenced by dance expertise (Bläsing, 2010). For example, Bläsing, Tenenbaum, and Schack (2009) compared the hierarchical structure of basic action concepts for ballet movements in professional dancers, amateurs, and non-dancers. The cognitive movement structures of experts and advanced amateurs, but not beginners or novices, were consistent with functional movement structures based on biomechanical principles. When spatial directions linked to movements were used as stimuli (Bläsing \& Schack, 2011), only professional dancers, as opposed to beginners or advanced amateurs, reflected a representation of functional movement structure.

In situations where dance material has been crafted and sequenced according to an underlying organizational structure, the structure can be considered a grammar or a rule that governs transitions. Studies are emerging that investigate the assumption that expert dancers predict when they watch dance and this prediction is based on memory for the dance material and transitions between movements, phrases and sections. For example, Opacic, Stevens, \& Tillmann (2009) have demonstrated that after intensive exposure to examples of dance transitions that conform to an artificial grammar, novice dance observers in a test phase are increasingly accurate at selecting new grammatical sequences. The greater accuracy of the exposure group versus the no-exposure control group is taken as evidence of the development 
of expectations or memory that enables prediction of dance material. Such a result is also significant for the development of dance audiences - perceptual fluency or familiarity develops through visual experience that, in turn, heightens preference and liking for the dance material.

In experts, intensive and extended exposure to dance likely develops schematic expectations for dance styles, choreographic traditions, and so on. Expectations about a particular dance piece, or so-called veridical expectations, may also develop while watching a performance. The hypothesis that dance experts have acquired expectations about dance that facilitate perception has been studied by measuring observers' eye movements. As in the comparison between fixation times in the eye movements of expert and novice drivers, athletes, and pilots, the fixation times of dance experts watching a dance film were significantly shorter than those of novice observers (Stevens, Winskel, Howell, Vidal, Latimer, \& Milne-Home, 2010). The dance experts' enhanced speed of visual processing suggests that they are adept at anticipating and processing dance material, possibly aided by acquired expectations in longterm memory concerning body and movement configurations. Contextual cues to long-term memory for dance movement, such as accompanying music, are being explored (Stevens, Ginsborg, \& Lester, 2011; Stevens, Schubert, Wang, Kroos, \& Halovic, 2009).

In this section, we have considered memory for dance material, item order, and transitions, and have seen that sequence structure, sometimes verbal rehearsal, and accompanying cues such as music aid encoding and recall. Current issues include the multimodal codes and cues in memory for movement, and the relationship between mere exposure, perceptual fluency, and preference. Research concerning imagery and spatial transformation in dance is reviewed in the next section. 


\section{Visuomotor Imagery and Spatial Transformation}

In dance training and performance, mental imagery of movement is frequently used as a tool for learning and optimizing movements. Dancers use mental imagery in creating new material (e.g., Fink, Graif, \& Neubauer, 2009; May, Calvo-Merino, deLahunta, Cusack, Owen, et al. 2011), to exercise the memorization of long complex phrases, and to improve movement quality in terms of spatiotemporal adaptation and artistic expression. Dance training has been found to increase the amount and efficiency of kinaesthetic imagery used and to enhance the imagery of kinaesthetic sensations, making images more complex and vivid (Golomer, Bouillette, Mertz, \& Keller, 2008; Nordin \& Cumming, 2007). In order to decrease physical stress, especially during recovery from injury, alternative dance training methods based on mental imagery have frequently been recommended (Krasnow, 1997). These studies corroborate evidence from dance practice by showing that dancers have learned to apply mental imagery more successfully and more consistently than dance novices and that they can even reproduce this ability under laboratory conditions. In this context it is feasible to ask: What mechanisms underlie the different types and aspects of motor imagery, and how and why do dancers benefit from using them?

The theory that motor imagery is based on simulation processes that recruit motor representations (Jeannerod, 1995, 2004) is supported by empirical findings. During motor imagery, increased cardiac and muscular activity can be observed, as well as increased cortical activity of high frequencies (beta activity) in a broad range of cortical areas, indicating states of high concentration and attention comparable to active movement (Blaser \& Hökelmann, 2004, 2009). Cortical circuits activated during motor imagery (to be described in the next section) overlap to a large extent with those activated during movement generation and movement observation. Imagery in the absence of sensory input specifically necessitates 
internal motor attention processes, evidenced by specific activation in the posterior insula and anterior cingulate gyrus (May et al. 2011; Munzert, Zentgraf, Stark, \& Vaitl, 2008).

It has previously been stated that experienced dancers, compared to novices, show increased expertise in kinesthetic imagery tasks, based on the common use of motor imagery in dance training. This notion has led to the assumption that dancers should also show enhanced skills in visual imagery, and specifically in mental transformation processes in which visuallypresented stimuli have to be mentally manipulated in spatial orientation from the observer's perspective. Studies involving mental rotation of visual stimuli revealed different cognitive processes for objects (e.g., Shepard \& Metzler, 1971) from that of human bodies or body parts (e.g., Parsons, 1987). Jola and Mast (2005) assumed that dancers should perform extremely well in mental rotation tasks involving human bodies, but their study found no such expertise effects in dancers compared to controls. In contrast, gymnasts and judo experts performed better than controls under comparable conditions (Weigelt, Steggemann, Bläsing \& Schack, 2008), suggesting that expertise in mental transformation might be axis-specific.

The fact that dancers show an advantage in studies investigating motor imagery, but display no such advantage in mental transformation tasks is likely due to characteristics specific to each kind of task. A comparison of findings from studies investigating active and attentive motor imagery and those investigating visually-presented mental transformation tasks on the other side suggests that dancers' expertise is more likely to involve the conscious and strategic use of motor imagery and motor simulation (as used in dance training), but does not seem to generalize to the mostly unconscious processes of covert action, as other classic motor preparation and mental transformation studies have suggested (Jeannerod, 2004). Current issues deriving from these results include the role of attentional focus in motor learning and performance, the relative efficiency of different types of motor imagery differing 
in parameters such as modality or perspective, and the underlying neurocognitive processes that link motor simulation to motor execution. As observation and motor imagery appear to share neural substrates, further related issues will be discussed in the following section.

\section{Neural Substrates of Action Observation}

While not all dance is performed for a large audience (such as participatory folk dances or social dancing in a nightclub), dance as a performing art implies the role or involvement of spectators. The neurocognitive mechanisms stimulated by watching movement in general have been widely studied in the human and non-human primate brain (for a review, see Rizzolatti \& Sinigaglia, 2010). Evidence from these studies suggests that when observing action, we internally simulate the observed movement using similar brain regions used to execute the movement with our own body. The network of regions shown to be active during movement execution, observation, and imagery includes inferior parietal and premotor cortices as core nodes, and has been described as the human mirror system (Grèzes \& Decety, 2001). Most early human mirror neuron studies used everyday hand actions (e.g., grasping) as stimuli, investigating neural responses to only a very limited portion of the complex human motor repertoire. Recently, several laboratories have turned to populations of expert and novice dancers to further delineate how the brain links action with perception, and how the mirror system may be engaged in the learning and observation of the coordinated full-body movements that are typical for dance.

The earliest work with dancers that used functional magnetic resonance imaging (fMRI) to explore how motor expertise shapes brain activity in action observation demonstrated that expert ballet and capoeira dancers (Calvo-Merino, Glaser, Grèzes, Passingham, \& Haggard, 2005), as well as contemporary dancers (Cross, Hamilton \& Grafton, 2006), show increased activity in brain areas considered to be part of the human mirror system while watching 
movements that they have learnt to perform (i.e., that have been acquired in their motor repertoire), compared with similar movements that they have not performed before.

Comparable findings have been obtained using electroencephalography (EEG) to investigate rhythmical brain activity when expert contemporary dancers and non-dancers watch dance movements and everyday actions (Orgs, Dombrowski, Heil, \& Jansen-Osmann, 2008). Dancers showed stronger de-synchronization of the motor cortex, taken as an indirect measure of motor simulation, while watching dance compared to non-dancers. Together, these studies using the expertise model highlight the utility of working with specialized populations of dancers to explore fundamental questions about how the brain links movement experience with perceptual processing.

Another line of research has attempted to further dissociate how responses within motor regions of the brain during action observation are modified by visual or motor experience. In one study, expert ballet dancers watched gender-neutral movements, observed and performed regularly by both male and female dancers, and gender-specific movements, observed regularly but never performed by the opposite sex (Calvo-Merino, Grèzes, Glaser, Passingham \& Haggard, 2006). The authors found that premotor and parietal regions demonstrate responses specifically tuned to motor familiarity of the observer, over and above responses seen in the same mirror system regions when the dancers watched movements that were visually familiar, but never executed. The second study used novice dancers learning simple dance sequences in a dance video game context, either by physical practice or passive observation (Cross, Kraemer, Hamilton, Kelley, \& Grafton, 2009b). Among this population, there were similarities between physical and observational learning within parietal and premotor mirror system regions, with performance data adding additional support to the notion that physical and observational learning shape the brain and behavior in a similar manner. These two studies suggest that the human action observation network may be more 
functionally apportioned and more responsive to sensorimotor experience than initially thought. Further evidence illustrating how dance experience shapes the nervous system is provided by a study investigating the impact of professional ballet training on the structure of and connectivity between sensorimotor brain regions (Hänggi, Koeneke, Bezzola, \& Jäncke, 2010). Hänggi and colleagues report clear evidence of intensive dance training reducing the volume of grey and white matter within sensorimotor cortical and subcortical regions, compared to non-dancers. Additional studies with expert dancers will help to enlighten the underlying components supporting the complex mechanisms linking dance experience with the structure and function of sensorimotor brain regions.

A number of challenges and opportunities exist for researchers who wish to work with dancers or dance paradigms to further investigate the neural underpinnings of action observation (e.g., Calvo-Merino, 2010; Cross, 2010; Jola, 2010). While exploring the neural architecture of dance observation continues to yield valuable insights about action-perception links, such experimentation will be improved by the development of behavioral measures that quantify how motor experience shapes perception. One recent study provides preliminary support for this claim, by demonstrating that ballet dancers' physical experience shapes their ability to discriminate movements they are adept at performing (Calvo-Merino, Ehrenberg, Leung, \& Haggard, 2010).

A further feature of action observation ripe for future exploration concerns how dance, which is often seen as a uniquely human expression, can help us to better understand how we perceive robotic agents (Cross, Liepelt, Hamilton, Parkinson, Ramsey, Stadler, \& Prinz, 2011; Miura, Sugiura, Takahashi, Sassa, Miyamoto, Sato, et al. 2010). A recent such investigation demonstrated that robots whose breakdancing movements are closely matched to a human breakdancer's movements are perceived as highly animate, human-like agents (Cross et al., 
2011). A challenge remains for future studies to advance these preliminary investigations, perhaps by exploring the neural and behavioral consequences of the social nature of dance. Further, a particularly intriguing and formidable issue for future work in this domain [it otherwise sounds very strange to me.] will be to bridge empirical research on dance observation with actual dance performance, in order to draw stronger conclusions about how motor and visual experience shapes perception not only among experienced dancers, but also among non-dancers and seasoned dance spectators.

While movement restrictions make it a daunting task to record brain responses in naturalistic dance contexts, researchers might take inspiration from Brown and colleagues, who pioneered a technique for studying the performance of tango steps while scanning dancers' brains with positron emission tomography (Brown, Martinez, \& Parsons, 2006). Another approach is to study actual dance performance from the spectators' point of view. These studies investigate how the brains of spectators who are not dancers themselves respond to watching live dance performances (Jola, Ehrenberg, \& Reynolds 2011; Jola, Pollick, \& Grosbras, 2011). This is indeed one of the most exciting new directions being pursued within this field, only just beginning to yield the first results. Development and testing of such paradigms promise to shed light on how non-dancers perceive dance, as well as to transcend typically reductionist evaluations of watching dance that are classically used in laboratory experiments. The aim of such studies is to perform experimental work while maintaining the fidelity of the dance performance (i.e., the choreographer's and performers' intentions). In the final section, we examine issues of aesthetic appreciation in more detail. [It's not correct otherwise and it is contradicting what we just write above]

\section{Aesthetics and Expression}


As is clear from the evidence reviewed in the previous section, the perception of another person's body in motion is substantially influenced by reciprocal top-down and bottom-up processes between the actor and observer (e.g., Blake \& Shiffrar, 2007). Dancers and choreographers apply this principle in their art, deliberately creating, modifying and shaping implicit and explicit messages of the moving body (see Stevens \& McKechnie, 2005). Studies have corroborated that dance conveys information about emotional states (Chicchella \& Bianchini 2004; Dittrich, Troscianko, Lea, \& Morgan, 1996; Sawada, Suda, \& Ishii, 2003) and the dancer's physical condition (Brown, Cronk, Grochow, Jacobson, Liu, Popovic, et al. 2005) to the observer. Laws and colleagues applied basic mechanical principles to analyse how dancers achieve typical aesthetic qualities when performing different types of ballet movements (Laws 1995, 1998; Laws \& Petrie 1999). Stevens, Malloch, McKechnie and Steven (2003) point out that the essence of novelty in artistic creativity may be metaphorical thinking, which provides a cognitive and emotional mode of communication between choreographer, performer, and observer.

To shed light on the art of dance in the context of neuroaesthetics, Calvo-Merino, Jola, Glaser, and Haggard (2008) used fMRI to determine brain activity related to subjective judgements of aesthetics. Subjects watched dance movements while performing irrelevant tasks, and later rated the movements along various aesthetic dimensions. High aesthetics ratings correlated with increased activity in the occipital cortices and in right premotor portion of the mirror system, suggesting that visual and sensorimotor brain areas might play a role in an automatic aesthetic response to dance. Another recent study aimed to quantify the relationship between an observer's physical ability to reproduce an observed dance sequence, and how much he or she liked watching it (Cross, Kirsch, Ticini, \& Schütz-Bosbach, 2011). These authors report that not only do dance-naïve participants enjoy watching difficult dance 
movements that they cannot physically perform, but this relationship between liking and a lack of physical ability appears to be mediated by parietal and occipital cortices.

A noteworthy feature of both fMRI neuroaesthetics studies performed to date (Calvo-Merino et al., 2008; Cross et al., 2011) is that they used a subjective approach that enabled them to closely examine which movements appealed most to their participants. In this way, CalvoMerino et al. (2008) were able to tell that the premotor region showed a preference for fast moves with vertical displacement, and Cross et al. (2011) reported that the more physically difficult participants perceived the movements to be, the more they were enjoyed. This type of subjective approach can be communicated to the dance community and, where there is interest, such information could be used to create a dance phrase aesthetically pleasant for the human brain (Calvo-Merino, 2010; Cross and Ticini, 2011; but see Jola, 2011; Jola, Ehrenberg, \& Reynolds, 2011 regarding the complexity of combining neuroscience and choreography). Transcranial magnetic stimulation (TMS) has been used recently to interfere with aesthetic judgments (Calvo-Merino, Urgesi, Orgs, Aglioti, \& Haggard, 2010). Application of magnetic pulses to sensorimotor regions such as premotor and extrastriate body area, showed the existence of a complementary network for aesthetic evaluation of dance body postures, hypothesized to include visual and motor regions. The accumulating set of fMRI and TMS experiments highlight the importance of sensorimotor mechanisms for the aesthetic experience of dance. This sensorimotor experience may be a reflection of high levels of embodiment (measured as somatosensory activity with somatosensory evoked potentials) during the aesthetic perception compared to mere visual perception (Calvo-Merino et al., 2011).

The intersection of dance and brain-based models of aesthetic appreciation is one that is ripe for further inquiry. As discussed and debated elsewhere (Calvo-Merino, 2010; Cross \& 
Ticini, 2011; Jackobson \& Calvo-Merino, submitted; Jola, Pollick \& Grosbras, 2011), the nascent field of neuroaesthetics offers opportunities for dancers and scientists to collaborate in order to gain a better understanding of how dance creation and expression is perceived and evaluated by audiences, and how this relationship might be modulated on both sides of the stage. As neuroimaging technologies continue to advance, we anticipate that research using scientific methods to better understand our relationship to dance will continue to attract interest from domains ranging from cognitive psychology, neuroscience, and cross-cultural psychology, to dance and choreography.

\section{Conclusion}

Performing and perceiving dance epitomizes embodied cognitive processes including those based on somatosensation, learning, memory, multimodal imagery, visual and motor perception, and motor simulation. Dance thus sheds a critical light on current experimental approaches in psychology and neuroscience by combining experimental paradigms with dancers' outstanding motor and cognitive skills. Therefore, dance has not only the potential to provide insights into cognitive, emotional, and aesthetic function and behaviour, but also it has the potential to impact contemporary scientific approaches. For this reason, the areas highlighted in this review are by no means the only avenues where future work in the psychological, cognitive and brain sciences might benefit from establishing liaisons with dance. Based on the research reviewed here, many new issues centered on the neurocognitive processes engaged by dance emerge that are ripe for future exploration, such as the effects of training on multimodal integration and memory encoding for movement, the role of attentional focus in motor learning and performance, the effects of motor experience on brain activity in response to live dance performance, the factors that shape neural responses in aesthetic experience, and positive effects of dance activity on wellbeing across the lifespan and applications in rehabilitation. Finally, as avatars and humanoid robots become more 
commonplace, there is an increasing demand for the generation of authentic biological motion in non-biological agents. Modelling the rich, complex biological motion patterns inherent in human dance might also help to enhance robot and avatar naturalness, which in turn should help us to further understand the neural and behavioral consequences of the social nature of dance. As interest from both the scientific and artistic communities for pursuing multidisciplinary research continues to gain momentum, we anticipate a growing number of reciprocal benefits to both fields. Such benefits will be further propagated by the fact that dance is an ever-changing art form. Although dance is a form of human expression that has been around since the dawn of human culture (Stehle, 1997), it has boomed in the $20^{\text {th }}$ century (Copeland and Cohen, 1983) with continually evolving styles and expressions (Daprati et al., 2009). This ever-expanding vocabulary of human expression will benefit from scientific investigation to remain adaptive, and will provide psychological and brain scientists a practically never-ending source of study. Taking the studies highlighted in this review as a point of departure, we encourage researchers from the behavioral and brain sciences to consider dance paradigms as a means to study questions ranging from motor control to the perception and coordination of social behavior. 


\section{Acknowledgements}

We are grateful to all the dancers and choreographers who participated in the studies described here. Beatriz Calvo-Merino was supported by the subprogram Ramon Y Cajal (MICINN-RYC) and a City University Fellowship (City University London). Emily S. Cross was supported by a fellowship from the Alexander von Humboldt Foundation. Juliane Honisch was supported by Qualisys (Sweden). Corinne Jola was supported by the Arts and Humanities Research Council project Watching Dance: Kinesthetic Empathy and University of Surrey Research Support. The authors thank Lauren R. Alpert for assistance with manuscript preparation. 


\section{References}

Allard, F., \& Starkes, J. L. (1991). Motor skill expertise in sports, dance and other domains. In K. A. Ericsson \& J. Smith (Eds.), Toward a general theory of expertise: prospects and limits (pp. 126-171). Cambridge: Cambridge University Press.

Blaser, P., \& Hökelmann, A. (2004). Relationships between load and demand under the condition of the mental representation of a dance. Journal of Human Kinetics 12, 1530.

Blaser, P., \& Hökelmann, A. (2009). Mental reproduction of a dance choreography and its effects on physiological fatigue in dancers. Journal of Human Sport and Exercise, $4(2), 129-141$.

Bläsing, B. (2010) The dancer's memory. In B. Bläsing, M. Puttke, \& T. Schack (Eds.), The neurocognition of dance: Mind, movement and motor skills (pp. 75-98). London: Psychology Press.

Bläsing, B., Puttke, M., \& Schack, T. (Eds.), The neurocognition of dance: Mind, movement and motor skills. London: Psychology Press.

Bläsing, B., \& Schack, T. (2011). Mental representations of spatial movement parameters in dance. Spatial Cognition and Computation. DOI: 10.1080/13875868.2011.626095.

Bläsing, B., Tenenbaum, G., \& Schack, T. (2009). The cognitive structure of movements in classical dance. Psychology of Sport and Exercise, 10(3), 350-360.

Blake, R., \& Shiffrar, M. (2007). Perception of human motion. Annual Review of Psychology, $58,47-73$.

Brown, S., Martinez, M. J., \& Parsons, L. M. (2006). The neural basis of human dance. Cerebral Cortex, 16(8), 1157-1167.

Brown, W. M., Cronk, L., Grochow, K., Jacobson, A., Liu, C. K., Popovic, Z., et al. (2005). Dance reveals symmetry especially in young men. Nature, 438(7071), 1148-1150.

Bruyneel, A.V., Mesure, S., Paré, J.C., \& Bertrand M. (2010) Organization of postural equilibrium in several planes in ballet dancers. Neuroscience Letters, 485 (3), 228232.

Calvo-Merino, B. (2010). Neural mechanisms for seeing dance. In B. Bläsing, M. Puttke, \& T. Schack (Eds.), The neurocognition of dance: Mind, movement and motor skills (pp. 153-176). London: Psychology Press.

Calvo-Merino, B., Ehrenberg, S., Leung, D., \& Haggard, P. (2010). Experts see it all: configural effects in action observation. Psychological Research, 74(4), 400-406. 
Calvo-Merino, B., Glaser, D. E., Grèzes, J., Passingham, R. E., \& Haggard, P. (2005). Action observation and acquired motor skills: an FMRI study with expert dancers. Cerebral Cortex, 15(8), 1243-1249.

Calvo-Merino, B., Grèzes, J., Glaser, D. E., Passingham, R. E., \& Haggard, P. (2006). Seeing or doing? Influence of visual and motor familiarity in action observation. Current Biology, 16(19), 1905-1910.

Calvo-Merino, B., Jola, C., Glaser, D. E., \& Haggard, P. (2008). Towards a sensorimotor aesthetics of performing art. Consciousness \& Cognition, 17(3), 911-922.

Calvo-Merino, B., Urgesi, C., Orgs, G., Aglioti, S. M., \& Haggard, P. (2010). Extrastriate body area underlies aesthetic evaluation of body stimuli. Experimental Brain Research, 204(3), 447-456.

Calvo-Merino, B., Gillmeister, H., Jones, A., Tziraki, M., Haggard, P., Forster, B. (2011). Somatotopic embodiment of aesthetic processing of human body postures. Front. Hum. Neurosci. Conference Abstract: XI International Conference on Cognitive Neuroscience (ICON XI). In press

Chatfield, S. J., Krasnow, D. H., Herman, A., \& Blessing, G. (2007). A descriptive analysis of kinematic and electromyographic relationships of the core during forward stepping in beginning and expert dancers. Journal of Dance Medicine and Science, 11(3), 9.

Chichella, C., \& Bianchini, K. (2004). Characteristics of movement and emotions elicited by two different kinds of dance. Journal of Human Kinetics 11, 59-68.

Cortese, A., \& Rossi-Arnaud, C. (2010). Working memory for ballet moves and spatial locations in professional ballet dancers. Applied Cognitive Psychology, 24, 266-286.

Copeland, R. \& Cohen, M. (1983) What Is Dance?. Oxford: Oxford University Press.

Cross, E. S. (2010). Building a dance in the human brain: Insights from expert and novice dancers. In B. Bläsing, M. Puttke, \& T. Schack (Eds.), The neurocognition of dance: Mind, movement and motor skills (pp. 177-202). London: Psychology Press.

Cross, E. S., Hamilton, A. F., \& Grafton, S. T. (2006). Building a motor simulation de novo: Observation of dance by dancers. Neuroimage, 31(3), 1257-1267.

Cross, E. S., Hamilton, A. F., Kraemer, D. J., Kelley, W. M., \& Grafton, S. T. (2009a). Dissociable substrates for body motion and physical experience in the human action observation network. European Journal of Neuroscience, 30(7),1383-92.

Cross, E. S., Kirsch, L., Ticini, L., \& Schütz-Bosbach, S. (2011). The impact of aesthetic appreciation and physical ability on dance perception. Frontiers in Human Neuroscience, 2011;5:102 
Cross, E. S., Kraemer, D. J., Hamilton, A. F., Kelley, W. M., \& Grafton, S. T. (2009b). Sensitivity of the action observation network to physical and observational learning. Cerebral Cortex, 19(2), 315-326.

Cross, E. S., Liepelt, R., Hamilton, A. F. d. C., Parkinson, J., Ramsey, R., Stadler, W., et al. (2011). Robotic actions preferentially engage the action observation network. Human Brain Mapping, Sep 6. DOI: 10.1002/hbm.21361.

Cross, E. S., \& Ticini, L. F. (2011). Neuroaesthetics and beyond: New horizons in applying the science of the brain to the art of dance. Phenomenology and the Cognitive Sciences, DOI: 10.1007/s11097-010-9190-y

Crotts, D., Thompson, B., Nahom, M., Ryan, S., \& Newton, R. A. (1996). Balance abilities of professional dancers on select balance tests. J Orthop Sports Phys Ther, 23(1), 12-17.

Daprati, E., Iosa, M., Haggard, P. (2009). A dance to the music of time: Aesthetically-relevant changes in body posture in performing art. PLoS One 4(3), e5023.

Dittrich, W. H., Troscianko, T., Lea, S., \& Morgan, D. (1996). Perception of emotion from dynamic point-light displays represented in dance. Perception, 25(6), 727-738.

Edwards, D. (2008). Artscience: Creativity in the post-Google generation. Cambridge: Harvard University Press.

Fink, A., Graif, B., \& Neubauer, A. C. (2009). Brain correlates underlying creative thinking: EEG alpha activity in professional vs. novice dancers. NeuroImage 46, 854-862.

Gentry, S., \& Feron, E. (2004). Musicality experiments in lead and follow dance. Paper presented at the IEEE Systems, Man and Cybernetics Conference.

Golomer, E., Bouillette, A., Mertz, C., \& Keller, J. (2008). Effects of mental imagery styles on shoulder and hip rotations during preparation of pirouettes. Journal of Motor Behavior, 40(4), 281-290.

Golomer, E., Cremieux, J., Dupui, P., Isableu, B., \& Ohlmann, T. (1999a). Visual contribution to self-induced body sway frequencies and visual perception of male professional dancers. Neuroscience Letters, 267(3), 189-192.

Golomer, E., \& Dupui, P. (2000). Spectral analysis of adult dancers' sways: sex and interaction vision-proprioception. International Journal of Neuroscience, 105(1-4), $15-26$.

Golomer, E., Dupui, P., \& Monod, H. (1997a). Sex-linked differences in equilibrium reactions among adolescents performing complex sensorimotor tasks. J Physiol Paris, 91(2), 49-55. 
Golomer, E., Dupui, P., \& Monod, H. (1997b). The effects of maturation on self-induced dynamic body sway frequencies of girls performing acrobatics or classical dance. Eur J Appl Physiol Occup Physiol, 76(2), 140-144.

Golomer, E., Dupui, P., Sereni, P., \& Monod, H. (1999b). The contribution of vision in dynamic spontaneous sways of male classical dancers according to student or professional level. J Physiol Paris, 93(3), 233-237.

Golomer, E., Mbongo, F., Toussaint, Y., Cadiou, M., \& Israel, I. (2010). Right hemisphere in visual regulation of complex equilibrium: the female ballet dancers' experience. Neurological Research, 32(4), 409-415.

Golomer, E., Rosey, F., Dizac, H., Mertz, C., \& Fagard, J. (2009a). The influence of classical dance training on preferred supporting leg and whole body turning bias. Laterality, 14(2), 165-177.

Golomer, E., Toussaint, Y., Bouillette, A., \& Keller, J. (2009b). Spontaneous whole body rotations and classical dance expertise: how shoulder-hip coordination influences supporting leg displacements. J Electromyogr Kinesiol, 19(2), 314-321.

Grahn, J. A., \& McAuley, J. D. (2009). Neural bases of individual differences in beat perception. Neuroimage, 47, 1894-1903.

Grèzes, J., \& Decety, J. (2001). Functional anatomy of execution, mental simulation, observation, and verb generation of actions: a meta-analysis. Human Brain Mapping, 12(1), 1-19.

Hänggi, J., Koeneke, S., Bezzola, L., Jäncke, L. (2010). Structural neuroplasticity in the sensorimotor network of professional female ballet dancers. Human Brain Mapping, 31(8), 1196-1206.

Hanna, J. L. (1979). To dance is human: A theory of nonverbal communication. Chicago: The University of Chicago Press.

Honisch, J. J., Roach, N., \& Wing, A. M. (2009). Movement synchronization to a virtual dancer: How do expert dancers adjust to perceived temporal and spatial changes whilst performing ballet versus abstract dance sequences? Paper presented at the ISSP 12th World Congress of Sport Psychology.

Hugel, F., Cadopi, M., Kohler, F., \& Perrin, P. (1999). Postural control of ballet dancers: a specific use of visual input for artistic purposes. International Journal of Sports Medicine, 20(2), 86-92.

Jackobson \& Calvo-Merino, B. (submitted). Dance: from movement to aesthetics. 
Jean, J., Cadopi, M., \& Ille, A. (2001). How are dance sequences encoded and recalled by expert dancers? Current Psychology of Cognition, 20, 325-337.

Jeannerod, M. (1995). Mental imagery in the motor context. Neuropsychologia, 33(11), 14191432.

Jeannerod, M. (2004). Actions from within. International Journal of Sport and Exercise Psychology, 2(4), $376-402$.

Jola, C. (2010). Research and choreography - merging dance and cognitive neuroscience. In B. Bläsing, M. Puttke, \& Th. Schack (Eds.), The neurocognition of dance. Mind, movement and motor skills (pp. 203-234). Psychology Press: Hove, UK.

Jola, C., Davis, A., Haggard, P. (2011). Proprioceptive integration and body representation: insights into dancers' expertise. Experimental Brain Research, 213(2-3), 257-265.

Jola, C., Ehrenberg, S., Reynolds, D. (2011). The experience of watching dance: phenomenological-neuroscience duets. Phenomenology and the Cognitive Sciences, DOI: 10.1007/s11097-010-9191-x.

Jola, C., \& Mast, F. W. (2005). Mental object rotation and egocentric body transformation: Two dissociable processes? Spatial Cognition and Computation, .5(2-3), 217 - 237.

Jola, C., Pollick, F., \& Grosbras, M. H. (2011). Arousal decrease in 'Sleeping Beauty': audiences' neurophysiological correlates to watching a narrative dance performance of 2.5 hrs. Dance Research Electronic, forthcoming.

Kirsh, D., Muntanyola, D., Jao, R. J., Lew, A., Sugihara, M. (2009). Choreographic methods for creating novel, high quality dance. In L.-L. Chen, L. Feijs, M. Hessler, S. Kyffin, P. L. Liu, K. Overbeeke \& B. Young (Eds.), Proceedings of the 5th International Workshop on Design and Semantics of Form and Movement (DeSForM). (pp. 188195). Taipei: National Taiwan University of Science.

Krasnow, D. (1997). C-I Training: The merger of conditioning and imagery as an alternative training methodology for dance. Medical Problems of Performing Artists, 12, 3-8.

Krasnow, D., Wilmerding, M. V., Stecyk, S., Wyon, M., Koutedakis, Y. (2011). Biomechanical Research in Dance: A Literature Review. Medical Problems of Performing Artists, 26(1), 3-23.

Laws, K. (1995). The physics and aesthetics of vertical movements in dance. Medical Problems of Performing Artists, 14, 41-47.

Laws, K. (1998). Momentum transfer in dance movement. Medical Problems of Performing Artists, 14, 136-145. 
Laws, K., \& Petrie, C. (1999). Momentum transfer in dance movement: vertical jumps. Medical Problems in Performing Artists, 14(3), 138-140.

Lepelley, M. C., Thullier, F., Koral, J., \& Lestienne, F. G. (2006). Muscle coordination in complex movements during Jete in skilled ballet dancers. Experimental Brain Research, 175(2), 321-331.

Maduell, M., \& Wing, A. M. (2007). The dynamics of ensemble: The case for flamenco. Psychology of Music, 35(4), 591-627.

May, J., Calvo-Merino, B., deLahunta, S., McGregor, W., Cusack, R., Owen, A., et al. (2011). Points in mental space: an interdisciplinary study of imagery in movement creation. Dance Research Electronic, forthcoming.

Minvielle-Moncla, J., Audiffren, M., Macar, F., \& Vallet, C. (2008). Overproduction timing errors in expert dancers. Journal of Motor Behavior, 40(4), 291-300.

Miura, N., Sugiura, M., Takahashi, M., Sassa, Y., Miyamoto, A., Sato, S., et al. (2010). Effect of motion smoothness on brain activity while observing a dance: an fMRI study using a humanoid robot. Social Neuroscience, 5(1), 40-58.

Munzert, J., Zentgraf, K., Stark, R., \& Vaitl, D. (2008). Neural activation in cognitive motor processes: comparing motor imagery and observation of gymnastic movements. Experimental Brain Research, 188(3), 437-444.

Nordin, S. M., \& Cumming, J. (2007) Where, when, and how: A quantitative account of dance imagery. Research Quarterly for Exercise and Sport, 78(4), 390-395.

Opacic, T., Stevens, C., \& Tillmann, B. (2009). Unspoken knowledge: Implicit learning of structured human dance movement. Journal of Experimental Psychology: Learning, Memory, and Cognition, 35(6), 1570-1577.

Orgs, G., Dombrowski, J. H., Heil, M., \& Jansen-Osmann, P. (2008). Expertise in dance modulates alpha/beta event-related desynchronization during action observation. European Journal of Neuroscience, 27(12), 3380-3384.

Parsons, L. M. (1987). Imagined spatial transformation of one's body. Journal of Experimental Psychology: General, 116(2), 172-191.

Perrin, P., Deviterne, D., Hugel, F., \& Perrot, C. (2002). Judo, better than dance, develops sensorimotor adaptabilities involved in balance control. Gait \& Posture, 15(2), 187 194.

Phillips-Silver, J., Toiviainen, P., Gosselin N., Piche, N., Nozaradan, S., Palmer, C., \& Peretiz, I. (2011). Born to dance but beat deaf: a new form of congenital amusia. Neuropsychologia, forthcoming. 
Ramsay, J. R., \& Riddoch, M. J. (2001). Position-matching in the upper limb: professional ballet dancers perform with outstanding accuracy. Clinical Rehabilitation, 15(3), 324330.

Rein, S., Fabian, T., Zwipp, H., Rammelt, S., \& Weindel, S. (2011) Postural control and functional ankle stability in professional and amateur dancers. Clinical Neurophysiology, forthcoming.

Ricotti, L., \& Ravaschio, A. (2011). Break dance significantly increases static balance in 9 years-old soccer players. Gait \& Posture 33(3), 462-465.

Rizzolatti, G., \& Sinigaglia, C. (2010). The functional role of the parieto-frontal mirror circuit: interpretations and misinterpretations. Nature Reviews Neuroscience, 11(4), 264-274.

Rossi-Arnaud, C. M., Cortese, A., \& Cestari, V. (2004). Memory span for movement configurations: the effects of concurrent verbal, motor and visual interference. Current Psychology of Cognition, 22, 335-349.

Sawada, M., Suda, K., \& Ishii, M. (2003). Expression of emotions in dance: relation between arm movement characteristics and emotion. Perceptual \& Motor Skills, 97(3 Pt 1), 697-708.

Schmit, J. M., Regis, D. I., \& Riley, M. A. (2005). Dynamic patterns of postural sway in ballet dancers and track athletes. Experimental Brain Research, 163(3), 370-378.

Shepard, R. N., \& Metzler, J. (1971). Mental rotation of three-dimensional objects. Science, 171(972), 701-703.

Smyth, M. M., \& Pendleton, L. R. (1990). Space and movement in working memory. Quarterly Journal of Experimental Psychology A, 42(2), 291-304.

Smyth, M. M., \& Pendleton, L. R. (1994). Memory for movement in professional ballet dancers. International Journal of Sport Psychology, 25, 282-94.

Starkes, J. L., Caicco, M., Boutilier, C., \& Sevsek, B. (1990). Motor recall of experts for structured and unstructured sequences in creative modern dance. Journal of Sport \& Exercise Psychology, 12, 317-321.

Starkes, J. L., Deakin, J. M., Lindley, S., \& Crisp, F. (1987). Motor versus verbal recall of ballet sequences by young expert dancers. Journal of Sport Psychology, 9, 222-230.

Starosta, W. (2000). Genetic or social determination of the direction of turns during physical exercises. Kineziologija, 18, 33-40.

Stehle, E. (1997). Performance and Gender in Ancient Greece: nondramatic poetry in its setting. Princeton University Press. 
Stevens, C., Ginsborg, J., \& Lester, G. (2011). Backwards and forwards in space and time: recalling dance movement from long-term memory. Memory Studies, 4, 234-250.

Stevens, C., Malloch, S., McKechnie, S., \& Steven, N. (2003). Choreographic cognition: The time-course and phenomenology of creating a dance. Pragmatics \& Cognition, 11(2), 297-326.

Stevens, C. \& McKechnie, S. (2005). Thinking in action: thought made visible in contemporary dance. Cognitive Processing, 6, 243-252.

Stevens, C., Schubert, E., Wang, S., Kroos, C., \& Halovic, S. (2009). Moving with and without music: scaling and lapsing in time in the performance of contemporary dance. Music Perception, 26(5), 451-464.

Stevens, C., Winskel, H., Howell, C., Vidal, L. M., Latimer, C., \& Milne-Home, J. (2010). Perceiving dance: schematic expectations guide experts' scanning of a contemporary dance film. Journal of Dance Medicine and Science, 14(1), 19-25.

Sugano, A., \& Laws, K. (2002). Physical analysis as a foundation for pirouette training. Medical Problems of Performing Artists, 17(1).

Thullier, F., \& Moufti, H. (2004). Multi-joint coordination in ballet dancers. Neuroscience Letters, 369(1), 80-84.

Toiviainen, P., Luck, G., \& Thompson, M. (2010). Embodied meter: hierarchical eigenmodes in music-induced movement. Music Perception, 28(1), 59-70.

Weigelt, M., Steggemann, Y., Bläsing, B., \& Schack, T. (2008). Über die Wahrnehmung menschlicher Figuren: eine Untersuchung zum Zusammenhang von Bewegungsexpertise und mentaler Rotation. In P. Khader, K. Jost, H. Lachnit \& F. Rosler (Eds.), Experimentelle Psychologie. Lengerich: Papst Science Publishers.

Wilson, M., Lim, B., \& Kwon, Y. (2004). 3-Dimensional kinematic analysis of grand rond de jambe en l'air: skilled versus novice dancers. Journal of Dance Medicine and Science, $8,108-115$.

Yarrow, K., Brown, P., \& Krakauer, J. W. (2009). Inside the brain of an elite athlete: the neural processes that support high achievement in sports. Nature Reviews Neuroscience, 10(8), 585-596. 